\title{
Estudo sobre práticas de evidenciação voluntária e recursos ambientais adotadas pelas empresas do setor de bens industriais listadas na BM\&F BOVESPA participantes do índice Brasil amplo 2013
}

O processo de globalização da economia tem gerado novas preocupações e objetivos para as organizações. Cada vez mais a sociedade vem se preocupando com questões que envolvem a maneira com que as empresas utilizam os recursos naturais e como elas vêm associando a Gestão Ambiental às suas estratégias de negócio. Com isso o presente trabalho teve como objetivo, identificar o que as empresas do setor de bens industriais, listadas no Índice Brasil Amplo 2013 da BM\&F BOVESPA evidenciam sobre gestão ambiental em seus relatórios anuais de administração. Foram coletados através dos Websites dessas empresas, os relatórios anuais de administração, onde foi feita uma análise de conteúdo. Através dessa análise foram observados 29 indicadores, subdivididos em 5 subtemas e estes por sua vez, organizados e ranqueados por frequência de apontamentos. Assim, foi possível encontrar um padrão de evidenciação entre as empresas através dos indicadores mais citados.

Palavras-chave: Gestão Ambiental; Índice Brasil Amplo; Evidenciação de Informações Voluntárias.

\section{Study about disclosure voluntary practices about environmental resources adopted by the companies from the industrial goods sectorlisted in the BM\&FBOVESPA participating of the broad Brazil 2013 index}

\begin{abstract}
The process of economic globalization has generated new concerns and goals for organizations. Increasingly, society has been concerned with issues involving the way that businesses use natural resources and how they are associating their Environmental Management business strategies. With this, the present study aimed to identify what companies in the Industrial Goods sector, listed on Broad Brazil Index 2013 BM \& FBOVESPA evidence on environmental management in their annual reports and administration. Were collected through the websites of these companies, and annual management reports, where a content analysis was performed. Through this analysis of 29 indicators, divided into five sub-themes, these turn-ranked and organized by frequency of notes, so it was possible to find a standard of disclosure among companies through the most cited indicators were observed.
\end{abstract}

Keywords: Environmental Management; Broad Brazil Index; Voluntary Disclosure of Information.

Topic: Engenharia Ambiental

Reviewed anonymously in the process of blind peer

Jaine Leticia Biondo

Instituto Federal de Educação, Brasil

http://lattes.cnpq.br/3315257506114018

tcraco@yaho.com.br

Leandro Lumbiere

tcraco@yahoo.com.br

\section{Tânia Craco}

Pontifícia Universidade Católica do Rio Grande do Sul, Brasil http://lattes.cnpq.br/0921686278600926

tcraco@yahoo.com.br

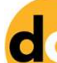

DOI: 10.6008/SPC2179-6858.2017.003.0015
Received: 12/03/2017

Approved: 12/05/2017

Uiliam Hahn Biegelmeyer

Universidade de Caxias do Sul, Brasil

http://lattes.cnpq.br/2397483078480061

uilicara@gmail.com

Referencing this:

BIONDO, J. L.; LUMBIERE, L.; CRACO, T.; BIEGELMEYER, U. H.. Estudo sobre práticas de evidenciação voluntária e recursos ambientais adotadas pelas empresas do setor de bens industriais listadas na BM\&F BOVESPA participantes do índice Brasil amplo 2013. Revista Ibero-Americana de Ciências Ambientais, v.8, n.3, p.159-169, 2017. DOI: http://doi.org/10.6008/SPC2179-6858.2017.003.0015 


\section{INTRODUÇÃO}

O processo de globalização da economia e o ingresso definitivo na era da informação têm feito com que as empresas se sintam obrigadas a seguir tendências mundiais no campo da divulgação dos seus atos e também, da evolução de seu patrimônio, o qual não mais Ihe pertence mas sim, a sociedade onde se encontra inserida, dando cumprimento à prestação de contas com responsabilidade, pois quanto mais credibilidade a empresa transmite à sociedade como um todo, mais compromisso assume com a mesma e mais respeito obtém (GONÇALVES et al., 2003).

Oliveira et al. (2009) definem as empresas como principais agentes no processo de desenvolvimento econômico, pois são as principais responsáveis pela intermediação dos recursos naturais e o consumidor final por meio do processo de industrialização. Seguindo esse raciocínio, entende-se que as empresas têm uma série de obrigações com a sociedade no que diz respeito a maneira com que utilizam estes recursos para produzirem bens e serviços. Paiva (2009) sugere que as empresas devem deixar transparecer um grau de preocupação e de amadurecimento elevado, demonstrando a existência de uma consciência ambiental desenvolvida. Desta forma, quando a empresa passa a valorizar sua relação com o meio ambiente e tomar medidas preventivas, sua imagem perante a opinião pública tende a apresentar conotação diferenciada.

Com base nesses argumentos, o presente trabalho tem por objetivo identificar através de relatórios anuais e de administração, quais são as categorias e itens representativos de informações evidenciadas sobre recursos ambientais de empresas do setor de bens industriais listadas na BM\&F BOVESPA e participantes do Índice Brasil Amplo em 2013.

Para encontrar a resposta deste problema, foram definidos 3 objetivos específicos: identificar as empresas listadas na BM\&FBOVESPA participantes do Índice Brasil Amplo pertencentes ao setor de bens industriais; identificar as categorias e os itens de informações evidenciadas nos relatórios anuais e de administração sobre recursos ambientais por meio da análise de conteúdo; e sintetizar os dados obtidos pela análise dos resultados e identificar um padrão de evidenciação de informações.

Este trabalho ficou limitado às empresas participantes da BM\&F BOVESPA, listadas no Índice Brasil Amplo. Desta forma, as empresas de capital aberto que não componham este índice não foram estudadas. O período de análise foi focado somente no ano de 2013. O estudo teve como base as informações divulgadas nos relatórios de administração e anual, retirados dos sites das empresas e da BM\&F BOVESPA e não foi utilizada outra fonte de pesquisa. A qualidade da informação sobre a evidenciação voluntária ambiental, não foi objeto de pesquisa e sim, se apresenta ou não a informação. Foram eliminadas as empresas financeiras pertencentes a este indicador, tendo em vista possuírem particularidades dos negócios das mesmas.

\section{REVISÃO TEÓRICA}

\section{Teoria da Agência}

A teoria da agência analisa os conflitos e os custos resultantes da separação entre propriedade e controle de capital. Essa possibilidade de não participação do acionista no gerenciamento da empresa é bem 
representada pela sociedade por ações, que limita a responsabilidade do acionista para com a organização à parcela de capital que ele investiu (MENDES, 2001).

Essa teoria foi formalizada por Jensen et al. (1976), onde eles introduziram a ideia de que a relação entre as partes é regida por contratos explícitos ou implícitos. Segundo eles a relação de agência é como um contrato no qual uma das pessoas (o principal) contrata outra pessoa (o agente) para desempenhar algum serviço como seu representante, envolvendo delegar algumas decisões e dando autoridade ao agente.

Porém, o fato de os gestores terem maiores informações sobre os projetos, riscos e valorização da empresa em relação aos seus investidores, faz com que acabe gerando uma assimetria de informação. Segundo Alencar (2005), os compradores de ações, por não terem total conhecimento das operações dos gestores das empresas que ofertam essas ações, tendem a diminuir o preço da oferta, como mecanismo de proteção e, por consequência, elevar o custo do capital próprio.

Yamamoto et al. (2006) destacam que se as empresas evidenciarem informações, terão uma repercussão positiva no mercado de valores mobiliários, contribuindo para uma melhor avaliação financeira da empresa, melhor retorno, melhor custo de captação e melhor flutuação de seus preços. Para os autores, no momento em que as empresas disponibilizam um grande número de informações pertinentes e voluntárias para o seu investidor, esses tendem a ficar mais confiantes e seguros, reduzindo os problemas de agência causados pela assimetria informacional.

\section{Evidenciação Voluntária}

Um dos objetivos da contabilidade é prover informações aos seus usuários para a tomada de decisões. Para Franco (2006), evidenciar pode ser entendido como o ato de a empresa revelar uma informação que seja de seu conhecimento privado. É um modo de transferir às partes interessadas conhecimento sobre a realidade das características e dos desempenhos da empresa.

A evidenciação é classificada basicamente como obrigatória ou voluntária (ALMEIDA, 2009). A evidenciação obrigatória é realizada por meio das demonstrações contábeis devidamente regulamentadas pela Lei 6.404/76 consolida e ainda por órgãos que têm a responsabilidade de regulamentar e fiscalizar o mercado de capitais no Brasil, representado pela Comissão de Valores Mobiliários (CVM).

Já a evidenciação voluntária é feita de maneira espontânea. Para Rover et al. (2009), esse tipo de informação pode reduzir a assimetria de informações, visto que a qualidade dessas informações permite que os usuários tenham informações diferenciadas das que são apresentadas nas demonstrações contábeis. Macagnan (2005) aponta que a evidenciação voluntária é causada por motivações, como: abertura de capital da empresa; preocupação da direção em explicar as perdas e ganhos da empresa; e ameaça de litigio. Dye (1986) diz que por trás de uma divulgação voluntária, sempre existe um interesse da empresa. Ele parte do pressuposto de que a empresa só irá fazer uma divulgação de uma informação de forma voluntária se esta for favorável. 


\section{Gestão Ambiental}

Os últimos 300 anos foram marcados por avanços tecnológicos inigualáveis. Diversas descobertas em todos os campos da ciência geraram uma incrível capacidade de produção e controle dos elementos naturais. No entanto, é também o período histórico em que o ser humano gerou meios que podem levá-lo a extinção. Os processos de urbanização e a revolução Industrial fizeram com que os problemas ambientais se agravassem, deflagrando assim num movimento que envolve indivíduos e organizações de todos os tipos com o objetivo de salvar o planeta (DIAS, 2011).

Dias (2011) define as empresas como as principais responsáveis pelo esgotamento e alterações ocorridas no meio ambiente natural. Segundo ele, a contaminação ambiental, do ponto de vista econômico, relaciona-se com a internalização dos custos externos, custos ambientais que o empresário causa mas não assume e que, acabam diminuindo seus custos diretos, já que não investe no processo produtivo para evitar a produção de resíduos contaminantes. Diante disso, o agravamento das condições ambientais provocou aumento da conscientização dos cidadãos, além de manter uma postura responsável de respeito a questão ambiental.

Essa questão ambiental, segundo Donaire (1995), está se tornando matéria obrigatória nas agendas dos executivos. Para Donaire (1995), a globalização dos negócios, internacionalização dos padrões de qualidade ambiental e a conscientização dos consumidores, têm feito com que as organizações incorporem variáveis ambientais na prospecção de seus cenários e na tomada de decisões, além de manter uma postura responsável de respeito a questão ambiental.

A gestão ambiental visa orientar a organização a evitar problemas ao meio ambiente, com o intuito de obter um desenvolvimento sustentável (DIAS, 2011). Para Nilson (1998), Gestão Ambiental envolve planejamento, organização e orienta a empresa a alcançar metas ambientais específicas em uma analogia parecida a que ocorre com a gestão da qualidade. Berry et al. (1998) destacam que a pressão dos Stalkeholders é o principal fator que leva as organizações a buscarem uma gestão ambiental mais avançada, que pode mudar a performance ambiental da empresa.

\section{Índice Brasil Amplo}

O Índice Brasil Amplo (IBRA) tem por objetivo ser o indicador de desempenho médio das cotações de todos os ativos negociados no mercado à vista (lote-padrão) da BM\&F BOVESPA e oferecer uma visão ampla do mercado acionário, medindo o comportamento das ações de todas as empresas que atendam a seus critérios de inclusão. As ações componentes são selecionadas por sua liquidez e ponderadas nas carteiras pelo valor de mercado das ações disponíveis na negociação (BM\&F BOVESPA, 2014). Para compor o Índice Brasil Amplo, as empresas devem seguir os seguintes critérios:

a) Estar entre os ativos elegíveis que, no período de vigência das 3 carteiras anteriores, em ordem decrescente de Índice de Negociabilidade, representem em conjunto $99 \%$ do somatório total desses;

b) Ter presença em pregão de $95 \%$ no período de vigência das 3 carteiras anteriores; 
c) Empresas com menos de doze meses de listagem somente são elegíveis se tiverem mais de seis meses de negociação e se apresentarem, no mínimo, $95 \%$ de presença em pregão nos últimos seis meses do período de análise (BM\&F BOVESPA, 2014).

Vale ressaltar que as empresas que estiverem sob regime de recuperação judicial, processo falimentar, situação especial ou que estiverem sujeitas a suspensão de negociação por um período prolongado, não integrarão o Índice. Porém, se estas empresas passarem a não estar mais nestas situações, seu histórico de negociação, começará a ser contado a partir da data em que a BM\&F BOVEPA considerar que a companhia tenha deixado a situação excepcional (BM\&F BOVESPA, 2014).

\section{METODOLOGIA}

Metodologia é todo o caminho que se traça para se atingir um objetivo qualquer. É um caminho que procura a verdade em um processo de pesquisa, ou aquisição de conhecimento que utiliza procedimentos científicos (MICHEL, 2009). Seguindo o conceito de Michel, este trabalho teve como objetivo identificar o que as empresas evidenciam sobre Gestão Ambiental em seus relatórios anuais e de Administração.

Para a definição dos procedimentos técnicos, o presente trabalho está classificado como pesquisa documental por meio de uma análise de conteúdo. Conforme Gil (2006), a pesquisa documental se vale de materiais que não receberam um tratamento analítico. Diante disso, foram analisados os dados secundários obtidos junto aos sites das empresas, sendo que os objetos de estudo foram os relatórios denominados de Relatórios Anuais e Relatórios de Administração, ambos publicados no ano de 2013.

O meio de pesquisa utilizado, foi a Evidenciação Descritiva, construindo um mapa das práticas de gestão ambiental apresentadas nos relatórios das empresas do setor de bens industriais, pertencentes ao índice Brasil Amplo 2013. Prodanov et al. (2013) definem pesquisa descritiva como registro e descrição dos fatos observados pelo pesquisador sem interferir neles. Ela visa descrever as características de determinada população ou fenômeno ou o estabelecimento de relações entre variáveis. Para melhor precisão da pesquisa o processo utilizado neste trabalho foi a Pesquisa Quantitativa que trata da atividade de pesquisa que usa a quantificação, tanto nas modalidades de coleta de informações quanto no tratamento dessas, através de técnicas estatísticas. Ela se realiza na busca de resultados precisos, exatos e comprovados através de medidas de variáveis pré-estabelecidas (MICHEL, 2009).

\section{População e amostra}

A presente pesquisa teve como população as empresas participantes da BM\&F BOVESPA, listadas no ano de 2013, que representam um total de 524 empresas. Sua amostra foi composta pelas empresas pertencentes ao Índice Brasil Amplo, com 138 empresas. A decisão de estudarmos esse índice deve-se ao fato de as empresas serem responsáveis por cerca de $99 \%$ da movimentação da Bolsa de Valores. Para a elaboração da amostra, ficou definido que apenas as empresas que publicaram os relatórios de Administração e Anual do ano de 2013 seriam estudadas. Empresas que não tiveram um dos relatórios publicados no ano de 2013, ou que tiveram publicações em anos anteriores, foram eliminadas da pesquisa. 
De um total de 138 empresas, 109 não publicaram os relatórios de Administração e/ou Anual do ano de 2013 e 3 não possuíam site, sendo assim eliminadas da pesquisa. Diante desse fato, a amostra desta pesquisa ficou composta por 26 empresas. Foi definido que apenas um setor seria o foco da nossa pesquisa. A figura 1 demonstra os setores com o número de empresas que publicaram os relatórios.

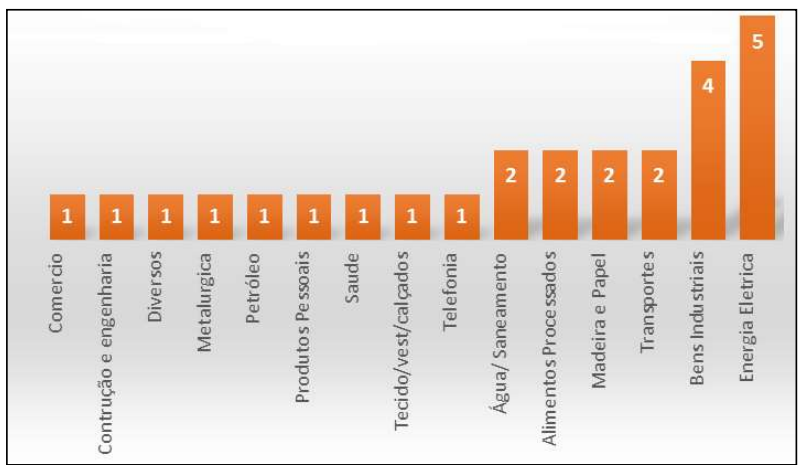

Figura 1: Número de empresas por setor que tiveram relatórios publicados em 2013.

Observa-se que dois setores apresentam um número relevante de empresas, quando comparado com os outros com publicações de relatórios no ano de 2013. O setor de energia elétrica com 5 empresas e o setor de bens industriais com 4 empresas. Pelo fato de as empresas pertencentes ao setor de energia elétrica serem administradas pelo governo, chegou-se à conclusão de que talvez as informações não fossem publicadas com a mesma preocupação de transparência das empresas privadas. Por isso, optamos por trabalhar com o setor de bens industriais. Assim, as empresas que foram analisadas nesse trabalho denominam-se: Embraer, Marcopolo, Mahle e Weg.

\section{Plano de Coleta e Tratamento dos Dados}

A coleta de dados foi feita em dois momentos: primeiramente foram coletados, junto aos sites das empresas que compõem a amostra, os relatórios anuais e de administração do ano de 2013. Posteriormente, esses dados foram verificados por meio de uma análise de conteúdo, através de leitura, onde buscamos identificar as informações que as empresas estavam divulgando ao mercado no que tange aos recursos de Gestão Ambiental. Para a apresentação dos dados, foram construídos quadros informativos a fim de identificar e classificar os termos e nomenclaturas utilizadas na evidenciação de informações sobre Gestão Ambiental, extraídas dos relatórios das empresas listadas no Índice Brasil Amplo.

\section{Análise e Discussão dos Resultados}

Após a definição do setor, leitura e analise dos relatórios anuais e de administração, foram identificados 29 indicadores. Estes, por sua vez, foram agrupados em 5 subtemas, definidos de acordo com grau de semelhança em que foram evidenciados. Estes subtemas compõem o tema objeto da pesquisa, aqui definido como: Meio Ambiente. A figura 2 apresenta o organograma onde consta tal divisão. 


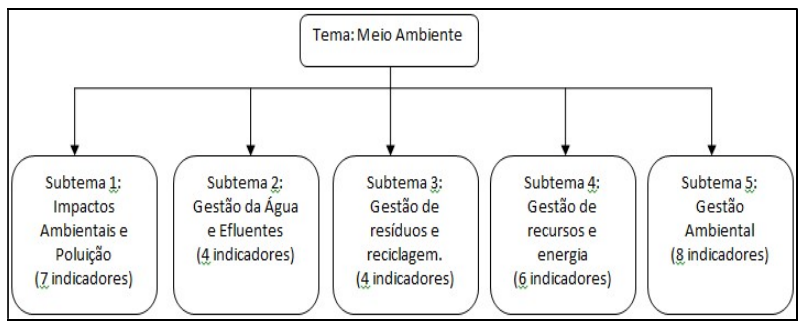

Figura 2: Organograma.

Observa-se que cada subtema foi composto por um número diferente de indicadores, onde foram classificados de acordo com o grau de semelhança das informações evidenciadas nos relatórios. A partir desses subtemas, foram construídos quadros, onde são apresentadas a quantidade de vezes que os indicadores foram citados. $\mathrm{O}$ quadro 1 apresenta os indicadores de acordo com seu número de evidenciações.

Quadro 1: $1^{\circ}$ Subtema: Impactos Ambientais e Poluição.

\begin{tabular}{|c|c|}
\hline Indicador & $\mathbf{N}^{\circ}$ de Evidenciação \\
\hline Gestão de Impactos Ambientais & 23 \\
\hline Monitoramento de Emissões de Gases Atmosféricos & 5 \\
\hline Controle e prevenção da Poluição & 2 \\
\hline Mitigação de riscos & 3 \\
\hline Preocupação com mudanças climáticas & 2 \\
\hline Recomposição do ecossistema & 4 \\
\hline
\end{tabular}

É possível constatar, observando o subtema, que o Indicador mais evidenciado foi o Monitoramento de Emissões de Gases Atmosféricos, com 23 citações, o que indica que as empresas procuram demonstrar preocupação com a quantidade de gases que emitem em seus processos produtivos e a encontrar formas de monitorar ou, até mesmo, diminuir essas emissões. Já, o menos evidenciado foi Recomposição do Ecossistema, demonstrando que esse indicador não traz tanta preocupação para as empresas. 0 quadro 2 apresenta o 2ㅇ Subtema denominado Gestão da Água e Efluentes.

Quadro 2: $2^{\circ}$ Subtema: Gestão da Água e Efluentes.

\begin{tabular}{|c|c|}
\hline Indicador & $\mathbf{N}^{\circ}$ de Evidenciação \\
\hline Tratamento dos efluentes & 12 \\
\hline Tratamento e gestão da água & 3 \\
\hline Redução do consumo de água & 4 \\
\hline Reutilização da Água & 5 \\
\hline
\end{tabular}

Este subtema foi constituído com informações evidenciadas sobre como as empresas lidam com o tratamento de efluentes, o tratamento da água e formas de redução do consumo e até reutilização. Pode-se observar que as empresas demonstram maior preocupação com a gestão e tratamento dos efluentes, onde aparecem 12 citações, que com tratamento e gestão da água utilizada em seus processos, que foi citada apenas 3 vezes. Por sua vez, o quadro 3 apresenta o Subtema intitulado Gestão de Resíduos e Reciclagem.

Quadro 3: $3^{\circ}$ Subtema: Gestão de Resíduos e Reciclagem.

\begin{tabular}{|c|c|}
\hline Indicador & $\mathbf{N}^{\circ}$ de Evidenciação \\
\hline Gerenciamento de resíduos & 3 \\
\hline Utilização de materiais recicláveis & 3 \\
\hline Reaproveitamento & 4 \\
\hline Utilização do conceito 3 R's (reduzir, reciclar, reutilizar) & 2 \\
\hline
\end{tabular}


Este subtema foi construído a partir de informações evidenciadas sobre formas de reaproveitamento e reciclagem dos materiais utilizados na fabricação de seus produtos, bem como destinação e tratamento dos resíduos gerados durante o seu processo produtivo. Observando o quadro, podemos verificar que as empresas têm grande preocupação com a forma de gerenciar os seus resíduos produzidos, sejam eles através do coprocessamento, reutilização ou destinação para um local correto. $O$ quadro 4 apresenta outro subtema.

Quadro 4: $4^{\circ}$ Subtema: Gestão de Recursos e Energia.

\begin{tabular}{|c|c|}
\hline Indicador & $\mathbf{N}^{\circ}$ de Evidenciação \\
\hline Gerenciamento de desperdícios & 4 \\
\hline Recuperação e controle do uso de recursos naturais & 7 \\
\hline Eficiência energética & 10 \\
\hline Redução do consumo de energia & 7 \\
\hline Geração de energias renováveis & 2 \\
\hline Fontes renováveis & 2 \\
\hline
\end{tabular}

Este subtema foi criado a partir de informações divulgadas sobre como as empresas fazem uso dos recursos naturais, como controlam seus desperdícios e ainda, questões do consumo de energia elétrica, evidenciando preocupação com a redução do consumo e otimização de sistemas de iluminação ou, até mesmo, geração de energias renováveis. Pode-se identificar nesse quadro, que há pouca variância no número de citações dos indicadores, demonstrando assim um padrão de preocupação das empresas com questões relacionadas a este subtema, mas a eficiência energética é o indicador que recebe maior número de citações. O Subtema Gestão Ambiental é apresentado no quadro 5.

Quadro 5: 5 Subtema: Gestão Ambiental.

\begin{tabular}{|c|c|}
\hline Indicador & $\mathbf{N}^{\circ}$ de Evidenciação \\
\hline Proteção Ambiental & 12 \\
\hline Educação Ambiental & 2 \\
\hline Meio Ambiente & 6 \\
\hline Atender a normas e metas ambientais & 18 \\
\hline Benefício Ambiental & 2 \\
\hline Responsabilidade ambiental & 4 \\
\hline Gestão Sustentável & 3 \\
\hline Práticas de Gestão Ambiental & 4 \\
\hline
\end{tabular}

Este subtema foi construído através de informações evidenciadas sobre como as empresas lidam com questões ligadas a Gestão e Proteção do Meio Ambiente, atendimento a normas e metas ambientais, fatores de responsabilidade ambiental, educação ambiental, gestão sustentável e os benefícios ambientais. Nesse subtema, pode-se verificar que as empresas procuram demonstrar maior preocupação com questões que tangem a proteção do meio ambiente, assim como ao atendimento das normas e metas ambientais, previstas pela Legislação. Os demais indicadores tiveram uma padronização no número de vezes que foram citados. Após a classificação dos dados, foi possível identificar quais os indicadores que foram mais evidenciados, independentes do seu subgrupo. A figura 3 apresenta os indicadores evidenciados.

Observa-se que o indicador 'Monitoramento de Emissões de Gases Atmosféricos' foi o mais evidenciado, com 23 citações. Considerando que este indicador foi citado 3 vezes pela empresa Marcopolo, uma vez pela empresa Mahle, dez vezes pela empresa Embraer e nove vezes pela empresa Weg, observouse que houve um padrão de evidenciação desta informação entre as empresas, mas que apenas duas delas o evidenciaram mais. 


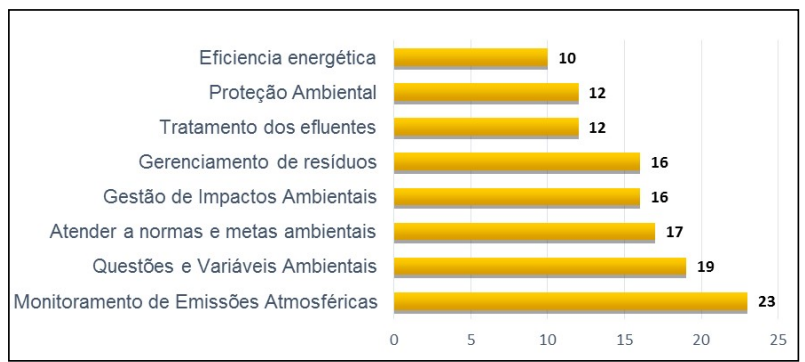

Figura 3: Indicadores Evidenciados.

O segundo indicador mais evidenciado, foi atender a normas e metas ambientais. Este indicador foi citado: oito vezes pela empresa Embraer, duas vezes pela empresa Marcopolo, e oito vezes pela empresa Weg. A empresa Mahle não evidenciou nada referente a este assunto. $O$ terceiro indicador mais evidenciado foi Gestão de Impactos Ambientais, onde teve cinco citações pela Embraer, quatro pela Marcopolo e sete pela Weg. A empresa Mahle também não evidenciou nada a respeito deste indicador.

O indicador Gerenciamento de resíduos, teve quaro evidenciações pela Embraer, duas evidenciações pela Mahle, sete pela Weg e cinco pela Marcopolo. Mostrando um equilíbrio na evidenciação das informações referentes a este indicador. $\mathrm{O}$ indicador tratamento de efluentes foi evidenciado duas vezes pela empresa Embraer, cinco vezes pela empresa Marcopolo e sete vezes pela empresa Weg. A empresa Mahle novamente não evidenciou nada. $O$ indicador Proteção Ambiental teve três citações pela empresa Embraer, uma pela empresa Marcopolo, nenhuma pela Mahle e oito pela Weg. Através dessas informações podemos verificar que ele está entre os mais evidenciados, devido a empresa Weg demonstrar maior preocupação com questões que envolvem proteção do meio ambiente. E o último indicador mais evidenciado foi eficiência energética, com dez citações, onde foi citado uma vez pela empresa Embrear e nove pela empresa Weg. As demais empresas não falaram nada relacionado ao indicador.

Verifica-se que quando relacionamos cada indicador mais evidenciado ao número de vezes que foi evidenciado por cada empresa, identificamos que a Weg e a Embraer, são as empresas que mais citam estes indicadores. A Marcopolo evidencia de forma mais moderada. Já a empresa Mahle, não demonstra grande preocupação em evidenciar esse tipo de informação, a qual foi identificada como um dos indicadores mais citados.

\section{CONSIDERAÇÕES FINAIS}

O presente trabalho teve como objetivo principal identificar através de relatórios anuais e de administração, quais são as categorias e itens representativos de informações evidenciadas sobre recursos ambientais de empresas do setor de bens industriais listadas na BM\&F BOVESPA e participantes do Índice Brasil Amplo em 2013. Para isso, foram coletados os relatórios através dos WebSites das empresas e feito uma filtragem, para que somente as que tivessem publicado os dois relatórios no ano de 2013 fossem foco da pesquisa.

Optou-se por trabalhar apenas com um setor. Ficou definido, portanto, que o foco da pesquisa seria o setor de bens industriais, devido a este ser um dos setores que mais possuem relatórios publicados e por 
serem empresas privadas. Após a coleta dos dados, foram construídos 29 indicadores, divididos em 5 subtemas, onde foi possível identificar um padrão de evidenciação entre as empresas.

Através dos dados obtidos nesse estudo foi possível concluir que as empresas do setor de bens industriais, demonstram sim interesse em evidenciar informações sobre gestão ambiental. Cada vez mais a preocupação com a gestão do meio ambiente vem sendo elencada as estratégias destas empresas, como forma de demonstrar um compromisso com a sociedade e seus stakeholders, uma vez que isso traz benefícios à organização, como por exemplo, reconhecimento por ser uma empresa ambientalmente responsável, entre outros.

Verificou-se que os indicadores mais evidenciados, geralmente estão associados aos assuntos que mais trazem preocupação à sociedade quando se fala sobre o meio ambiente, como por exemplo, preocupação com a emissão de gases atmosféricos que são um dos grandes causadores de poluição, preocupação em atender as normas ambientais, que demonstra compromisso com o cumprimento das leis, formas de gestão que contribuam para a redução de impactos ambientais, gerenciamento dos resíduos, tratamento de efluentes, a fim de diminuir o descarte em excesso desses elementos na natureza, redução do consumo de energia, buscando soluções de eficiência energética e, é claro, proteção do meio ambiente onde atuam.

Identificou-se também que algumas empresas demonstram maior preocupação em evidenciar informações sobre o meio ambiente do que outras. A empresa WEG é a que mais evidencia informações, pois se formos comparar os indicadores, os que têm mais citações, geralmente foram encontradas nos relatórios desta empresa. Já a empresa Mahle, fala sobre gestão ambiental em seus relatórios, porém não evidencia tanto.

Podemos verificar que as empresas evidenciam mais sobre determinados subtemas do que outros, como no caso da WEG, que fala mais sobre gerenciamento de recursos e energia, e a Embraer que destaca mais informações sobre impactos ambientais e poluição. Isso se deve ao fato de as empresas associarem essas estratégias de melhoria, com suas estratégias de negócio, visto que geralmente divulgam para o mercado a sua preocupação e empenho para tornar-se mais eficiente na solução de problemas atrelados ao seu setor e aos seus produtos.

Para o presente estudo o principal limitador foi o tempo de pesquisa e o foco em somente um setor e se basear apenas nas informações publicadas no ano de 2013, podendo assim distorcer a realidade das informações. Fica, portanto como sugestões de pesquisa, trabalhar com publicações de anos anteriores, para identificar se as empresas trabalham com um padrão de evidenciação das informações, e trabalhar com os outros setores, para verificar se as empresas também evidenciam a respeito do que foi encontrado neste trabalho, ou se podem ser identificados outros indicadores. Outra sugestão de pesquisa relevante sobre o tema, seria identificar o real motivo das empresas evidenciarem essas informações, se é por reconhecimento no mercado, ou por outras razões. 


\section{REFERÊNCIAS}

ALENCAR, R. C.. Custo do capital próprio e nível de disclosure nas empresas brasileiras. Brazilian Business Review, v.2, n.1, p.1-12, 2005.

ALMEIDA, L. B; FREITAG, V. C.. Evidenciação Contábil. In: RIBEIRO FILHO, J. F.; LOPES, J.; PEDERNEIRAS, M.. Estudando Teoria da Contabilidade. São Paulo: Atlas, 2009. p.265-281.

BERRY, M. A.; RONDINELLI, D. A.. Gestão ambiental proativa: Uma nova revolução Industrial. Academy of Management Executive, v.12, n.2, p.38-50, 1998.

DIAS, R.. Gestão Ambiental: responsabilidade e sustentabilidade. 2 ed. São Paulo: Atlas, 2011.

DONAIRE, D.. Gestão Ambiental na empresa. São Paulo: Atlas, 1995.

DYE, R. A.. Proprietary and nonproprietary disclosures. Journal of Business, v.59, n.2, p.331-366, 1986.

FRANCO, H.. Contabilidade Geral. 23 ed. São Paulo: Atlas, 2006.

GIL, A. C.. Como elaborar projetos e pesquisa. 4 ed. São Paulo: Atlas, 2006.

GONÇALVES, O.; OTT, E.. Pesquisa sobre a evidenciação contábil nas companhias de capital aberto com atuação no Brasil. In: CONVENÇÃO DE CONTABILIDADE DO RIO GRANDE DO SUL, 9. Anais. Gramado: CRCRS, 2003.

JENSEN, M. C.; MECKLING, W. H.. Theory of the Firm: Managerial Behavior, Agency Costs and Ownership Structure. Journal of Financial Economics, v.3, n.4, p.305360, 1976.
MACAGNAN, C. B.. Factores explicativos de la revelación de información de activos intangibles de empresas que cotizan em españa. Barcelona: Universitat Autònoma de Barcelona, 2005.

MENDES, A. P. S.. Teoria da Agência Aplicada à Análise de Relações entre os Participantes dos Processos de Cooperação Tecnológica Universidade-Empresa. Tese (Doutorado em Administração) - Faculdade de Economia, Administração, Contabilidade e Atuária, São Paulo, 2001.

MICHEL, M. H.. Metodologia e Pesquisa Científica em Ciências Sociais. São Paulo: Atlas, 2009.

MURCIA, F. D. R.. Fatores determinantes do nível de Disclosure voluntário de companhias abertas no Brasil. Tese (Doutorado em Ciências Contábeis) - Universidade de São Paulo, São Paulo, 2009.

PRODANOV, C. C.; FREITAS, E. C.. Metodologia do trabalho científico: métodos e técnicas da pesquisa e do trabalho acadêmico. 2 ed. Novo Hamburgo: Feevale, 2013.

ROVER, S.; BORBA, J. A.; MURCIA, F. D. R.. Características do disclosure ambiental em empresas brasileiras potencialmente poluidoras: análise das demonstrações financeiras dos relatórios de sustentabilidade do período de 2005 a 2007. Contextus Revista Contemporânea de Economia e Gestão, v.7, n.1, p.23-36, 2009.

SALOTTI, B. M.; YAMAMOTO, M. M.. Ensaio sobre a teoria da Divulgação. Brazilian Busines Review, v.2, n.1, p.53-70, 2005.

YAMAMOTO, M. M.; MALACRIDA, M. J. C.. Governança corporativa: nível de evidenciação das informações e sua relação com a volatilidade das ações do Ibovespa. Revista Contabilidade e Finanças USP, São Paulo, p.65-79, 2006. 